NOTES

\title{
Superacids and Their Derivatives XI. Cyclooligomerization of Ethylene Oxide Catalyzed by a Solid Superacid of Nafion-H
}

\author{
Shiro KobAyASHI and Takeo SAEgusA \\ Department of Synthetic Chemistry, Kyoto University, \\ Yoshida, Sakyo-ku, Kyoto 606, Japan
}

(Received December 23, 1983)

\begin{abstract}
KEY WORDS Solid Superacid / Nafion-H / Ethylene Oxide / Cyclooligomerization / Crown Ether /
\end{abstract}

Crown ethers can be considered as cyclic oligomers of ethylene oxide (EO). Cyclooligomerization of EO, therefore, is an attractive method to prepare crown ethers ${ }^{1,2}$ in a practically large scale for commercial uses, because the method is a single-step reaction and because EO is an industrially important monomer. The extension of our studies on polymerizations of cyclic ethers ${ }^{3}$ and on the cyclodimerization of $\mathrm{EO}^{4}$ catalyzed by superacids and their derivatives, led to a resin of perfluorinated sulfonic acid (Nafion-H, a solid superacid) which was employed as a catalyst for the reaction of EO. It has been found that the reaction underwent the oligomerization of EO to produce cyclic oligomers of EO selectively. The amount of these cyclic oligomers

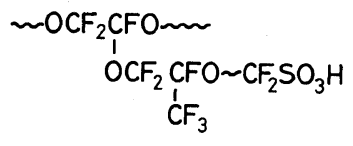

Nafion-H

was quantitatively determined as crown ethers being produced in a significant amount. As to a solid superacid catalyst, Nafion- $\mathrm{H}$ has been used extensively for Friedel-Crafts type reactions in organic synthesis 5 and for oligomerization of styrene. ${ }^{6}$

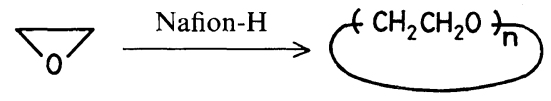

\section{EXPERIMENTAL}

\section{Materials}

EO was supplied from Meisei Kagaku Co. (Kyoto) and distilled before use. Nafion-H (the protonic acid form) was prepared from potassium salt of powdery Nafion-501 resin which was given from du Pont Co. Nafion-501 was treated with $4 \mathrm{~N}-\mathrm{HNO}_{3}$ followed by $\mathrm{FSO}_{3} \mathrm{H}$ and dried at $120-140^{\circ} \mathrm{C}$ for 2 days in vacuo with aspirator to give a white powdery resin of Nafion-H. ${ }^{5}$ The back-titration of Nafion-H gave proton concentrations of $0.16 \mathrm{mmol} \mathrm{g}^{-1}$-resin. $\mathrm{CF}_{3} \mathrm{SO}_{3} \mathrm{H}$ was obtained from $3 \mathrm{M}$ Chemical Co. and used without further purification. All solvents were purified by distillation before use. 12-Crown-4, 15crown-5, and 18-crown-6 (Aldrich Co.) were commercially obtained.

\section{Cyclooligomerization}

All reactions were carried out in a sealed tube under nitrogen. The reaction procedure of No. 1 (Table I) is given as a typical example. In a test tube Nafion-H $(50 \mathrm{mg}, 0.16 \mathrm{mmol}$ 
Table I. Cyclooligomerization of ethylene oxide (EO) catalyzed by Nafion- $\mathrm{H}^{\mathrm{a}}$

\begin{tabular}{|c|c|c|c|c|c|c|c|c|c|c|}
\hline \multirow{2}{*}{ No. } & \multirow{2}{*}{ Solvent } & \multirow{2}{*}{$\begin{array}{l}\text { Reaction } \\
\text { temp }\end{array}$} & \multirow{2}{*}{$\frac{\begin{array}{c}\text { Reaction } \\
\text { time }\end{array}}{\mathrm{h}}$} & \multirow{2}{*}{$\begin{array}{c}\begin{array}{c}\text { Conversion } \\
\text { of EO }\end{array} \\
\%\end{array}$} & \multicolumn{6}{|c|}{$\begin{array}{l}\text { Fraction of cyclic } \\
\text { oligomers } / w t \%\end{array}$} \\
\hline & & & & & $n=2$ & 3 & 4 & 5 & 6 & 7 \\
\hline 1 & $\mathrm{CHCl}_{3}$ & r.t. & 45 & 100 & 80.5 & 0.2 & 2.6 & 9.1 & 4.3 & 3.3 \\
\hline $2^{\mathrm{b}}$ & $\mathrm{CHCl}_{3}$ & $0^{\circ} \mathrm{C}$ & 190 & 41 & 86.2 & 0.5 & 1.8 & 5.8 & 4.1 & 1.8 \\
\hline 3 & - & $0^{\circ} \mathrm{C}$ & 190 & 48 & 87.2 & 0.1 & 2.1 & 6.4 & 2.7 & 1.5 \\
\hline 4 & $\mathrm{CH}_{2} \mathrm{Cl}_{2}$ & r.t. & 168 & 100 & 92.6 & 0.1 & 1.8 & 2.8 & 1.4 & 1.2 \\
\hline 5 & $\mathrm{C}_{6} \mathrm{H}_{6}$ & $0^{\circ} \mathrm{C}$ & 270 & 62 & 89.4 & 0.4 & 1.6 & 5.2 & 1.8 & 1.4 \\
\hline 6 & $\mathrm{C}_{6} \mathrm{H}_{6}$ & r.t. & 66 & 80 & 87.6 & 0.2 & 1.2 & 5.8 & 2.9 & 2.3 \\
\hline 7 & $\mathrm{CH}_{3} \mathrm{CN}$ & r.t. & 230 & 22 & 83.8 & 0.2 & 2.6 & 9.8 & 2.5 & 1.1 \\
\hline 8 & $\mathrm{CH}_{3} \mathrm{CN}$ & $0^{\circ} \mathrm{C}$ & 270 & 15 & 70.1 & 0.5 & 4.6 & 16.9 & 5.0 & 2.9 \\
\hline $9^{c}$ & $\mathrm{CHCl}_{3}$ & $0^{\circ} \mathrm{C}$ & 20 & 100 & 93.1 & 0.2 & 0.9 & 2.5 & 1.8 & 1.5 \\
\hline
\end{tabular}

${ }^{\mathrm{a}} \mathrm{EO}(5.0 \mathrm{mmol})+$ Nafion-H catalyst $\left(50 \mathrm{mg}=0.16 \mathrm{mmol}\right.$ of $\left.\mathrm{H}^{+}\right)$in $0.2 \mathrm{ml}$ of solvent in a sealed tube unless otherwise indicated.

b The Nafion-H catalyst recovered from No. 1 was reused after keeping it for 60 days in air at room temperature.

c $\mathrm{CF}_{3} \mathrm{SO}_{3} \mathrm{H}(0.2 \mathrm{mmol})$ was used as catalyst instead of Nafion-H.

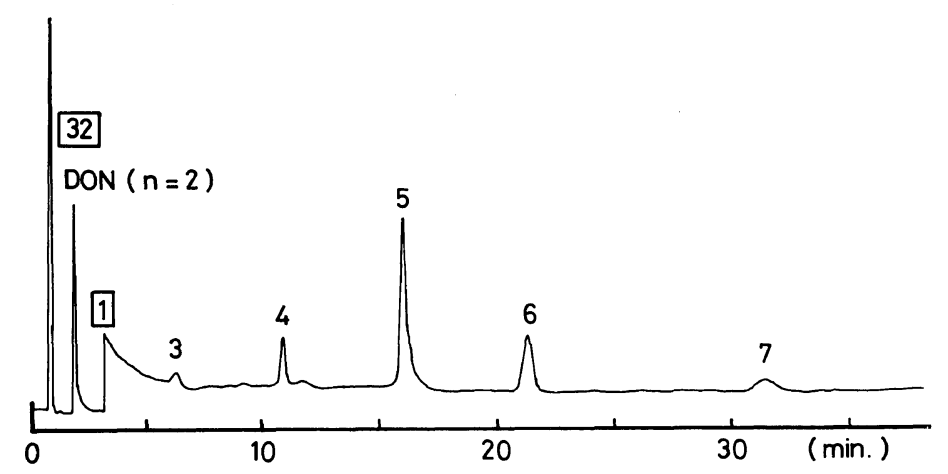

Figure 1. Gas chromatographic (GC) chart of the cyclooligomerization products of EO catalyzed by Nafion-H. Peak numbers indicate the number of EO unit of cyclic oligomers. $\overline{32}$ and 11 show the sensitivity of the GC detector. Column temperature was raised from $50^{\circ} \mathrm{C}$ to $220^{\circ} \mathrm{C}$ at the rate of $10^{\circ} \mathrm{C} \mathrm{min}^{-1}$.

equivalent of the acid) was placed under nitrogen and $0.2 \mathrm{ml}$ of $\mathrm{CHCl}_{3}$ was added to it. Into the tube kept at $-78^{\circ} \mathrm{C} \mathrm{EO}(5 \mathrm{mmol})$ was introduced by distillation. Then, the tube was sealed and kept standing with occational shaking at room temperature for $45 \mathrm{~h}$. The tube was cooled to $0^{\circ} \mathrm{C}$ and opened. The supernatant reaction mixture was transferred by using a syringe into an NMR sample tube at $0^{\circ} \mathrm{C}$ which was sealed and subjected to ${ }^{1} \mathrm{H}$ NMR measurement. The ${ }^{1} \mathrm{H}$ NMR analysis of the mixture revealed that the peak of EO $(\delta 2.5)$ disappeared and new signals due to open-chain oxy-ethylene units appeared at $\delta 3.5(100 \%$ conversion of EO).

Products were analyzed by gas chromatography (GC) (Shimadzu GC 6A gas chromatograph with a column packed with Silicon DC550 using hydrogen gas carrier at 1.5 $\mathrm{kg} \mathrm{cm}^{-2}$ ) with raising the column temperature at the rate of $10^{\circ} \mathrm{C} \mathrm{min}-1$ from the starting temperature of $50^{\circ} \mathrm{C}$. After $17 \mathrm{~min}$ later, the column temperature reached $220^{\circ} \mathrm{C}$ and this temperature was kept thereafter. Under these GC conditions the retention times of cyclic oligomers were $1.8 \mathrm{~min}$ (dimer), $6.0 \mathrm{~min}$ (trimer), $11.0 \mathrm{~min}$ (tetramer), $16.0 \mathrm{~min}$ (pentamer), $21.0 \mathrm{~min}$ (hexamer), and $31.0 \mathrm{~min}$ 
(heptamer) (Figure 1), respectively. Authentic cyclic oligomers of tetramer, pentamer, and hexamer were used to assign the $\mathrm{GC}$ retention times of each products. Cyclic oligomers higher than octamer were not detected.

\section{RESULTS AND DISCUSSION}

\section{Heterogeneous Cyclooligomerization by Nafion- $H$}

Cyclooligomerization of EO catalyzed by a powdery resin of Nafion-H was performed in a sealed tube with occasional shaking at $0^{\circ} \mathrm{C}$ or at room temperature (No. $1-8$, Table I). For example, ${ }^{1} \mathrm{H}$ NMR analysis of the reaction No. 1 carried out in $\mathrm{CHCl}_{3}$ solvent showed the complete consumption of EO after $45 \mathrm{~h}$ at room temperature. The GC analysis of the reaction mixture revealed that cyclic oligomers of EO (crown ethers) were produced in a fairly large amount although 1,4-dioxane (DON) was the largest in amount among these cyclic products (Figure 1). In addition to these, unidentified peaks were observed in the GC chart, which might be probably due to linear oligomers. The amount of cyclic oligomers exceeded at least $80 \%$ of the consumed EO in every run. Solvent effects on the cyclooligomerization were not clear. In $\mathrm{CH}_{3} \mathrm{CN}$, the consumption of EO was slow and the selectivity of crown ethers, however, was remarkably enhanced, e.g., the production of 15crown-5 reached $16.9 \%$ yield (No. 8 ). Without solvent the reaction (No. 3) proceeded almost the same as the $\mathrm{CHCl}_{3}$ system. It is to be noted that Nafion-H could be used again without decreasing the catalyst activity (No. 2). In addition, the treatment of 18 -crown-6 $(8.0 \mathrm{mmol}$ equivalent to $\mathrm{EO}$ unit) with $0.90 \mathrm{mmol}$ of Nafion- $\mathrm{H}$ in $2.0 \mathrm{ml}$ of $\mathrm{CHCl}_{3}$ did not cause any change of 18 -crown- 6 after $58 \mathrm{~h}$ at $25^{\circ} \mathrm{C}$. This result suggests that the produced crown ethers are not isomerized during the reaction by Nafion-H catalyst, which shows a sharp contrast to results ${ }^{2}$ that the produced oligomers from EO changed by a Lewis acid catalyst to a more thermodynamically stable DON.

\section{Homogeneous Cyclooligomerization by $\mathrm{CF}_{3} \mathrm{SO}_{3} \mathrm{H}$}

A homogeneous catalyst corresponding to Nafion-H is a liquid superacid of $\mathrm{CF}_{3} \mathrm{SO}_{3} \mathrm{H}$. The reaction of $\mathrm{EO}$ catalyzed by $\mathrm{CF}_{3} \mathrm{SO}_{3} \mathrm{H}$, therefore, was examined in comparison with the catalytic behavior of Nafion-H. As seen in reaction No. 9 (Table I) the catalytic activity of $\mathrm{CF}_{3} \mathrm{SO}_{3} \mathrm{H}$ was much higher than that of Nafion-H. However, the production of crown ethers was much less and the total amount of cyclic oligomers was also less; at most $70 \%$ of EO. In addition, a separate experiment showed that $\mathrm{CF}_{3} \mathrm{SO}_{3} \mathrm{H}$ did not induce any isomerization of 18 -crown- 6 in $\mathrm{CH}_{2} \mathrm{Cl}_{2}$ at $25^{\circ} \mathrm{C}$ for $20 \mathrm{~h}$; crown ethers such as DON being resistant to isomerization by a protonic acid catalyst like $\mathrm{CF}_{3} \mathrm{SO}_{3} \mathrm{H}$. This is in contrast to an oxonium catalyst ${ }^{2}$ or a Lewis acid catalyst ${ }^{1 \mathrm{~d}}$ which caused an isomerization of crown ethers.

\section{Reaction Mechanism}

A heterogeneous catalysis by Nafion- $\mathrm{H}$ is characterized by a higher selectivity of the production of crown ethers. This characteristic may be explained according to Scheme 1. Oligomerization of EO by a superacid catalyst proceeds via ester species and/or cyclic oxonium species. ${ }^{3,4}$ With Nafion- $\mathrm{H}$ or $\mathrm{CF}_{3} \mathrm{SO}_{3} \mathrm{H}$ catalyst, a linear oligomer having an $\mathrm{OH}$ group at the end is first to be formed. Then, two intramolecular reactions will take place; back-biting reaction (course A) and tail-biting reaction (course B). These two courses are intramolecular competitive reactions. The tailbiting is probably more readily to occur than the back-biting if the same cyclic product is formed because proton is a better leaving group than an oxyethylene chain. It is likely that crown ethers are mainly produced via course B rather than course A. With Nafion-H catalyst, course A becomes less probable due to the steric hindrance in the polymer matrix 
Nafion $-\mathrm{H}\left(\mathrm{F}-\mathrm{SO}_{3} \mathrm{H}\right)$
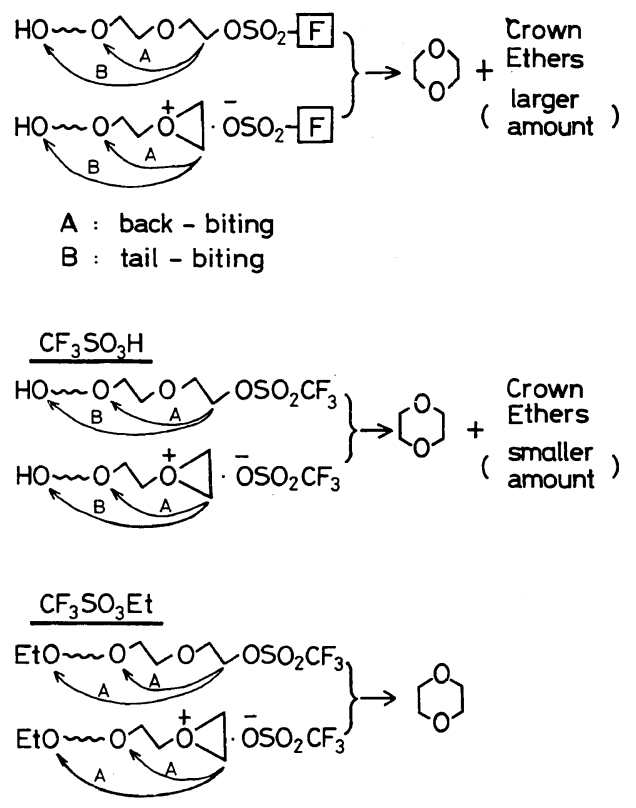

Scheme 1

of Nafion resin. Therefore the Nafion-H system possesses a higher probability to proceed to linear oligomers of several EO units whose tail-biting reaction gives rise to crown ethers. With a homogeneous catalyst of $\mathrm{CF}_{3} \mathrm{SO}_{3} \mathrm{H}$, on the other hand, such a steric situation is not present. Thus, the formation of crown ethers is more preferable with Nafion-H than with $\mathrm{CF}_{3} \mathrm{SO}_{3} \mathrm{H}$. Finally, the superacid ester $\left(\mathrm{CF}_{3} \mathrm{SO}_{3} \mathrm{Et}\right)$ system does not involve the tailbiting course since no $\mathrm{OH}$ group (tail) is present at the end. This situation will rationalize the predominant formation of DON with the ester catalyst via the back-biting (course
A), as the production of crown ethers is negligible in very small amount. ${ }^{4}$

\section{CONCLUSION}

Nafion-H is an effective catalyst for the cyclooligomerization of EO to give crown ethers with higher selectivity. It is a powdery resin and hence, is easy to handle; the catalyst is able to separate from the reaction mixture by a simple filtration. The catalyst can be used repeatedly without a decrease in the catalyst activities.

\section{REFERENCES}

1. (a) J. Dale, G. Borgen, and K. Daasvatn, Acta Chem. Scand., B28, 378 (1974); (b) J. Dale, G. Borgen, and K. Daasvatn, Ger. Patent Off., 2401126 (1974); (c) J. Dale and K. Daasvatn, J. Chem. Soc., Chem. Commun., 295 (1976); (d) J. Dale, K. Daasvatn, and T. Grønnberg, Makromol. Chem., 178, 873 (1977).

2. S. Kobayashi, T. Kobayashi, and T. Saegusa, Polym. J., 15, 883 (1983).

3. (a) S. Kobayashi, H. Danda, and T. Saegusa, Bull. Chem. Soc. Jpn., 46, 3214 (1973); (b) S. Kobayashi, N. Tsuchida, K. Morikawa, and T. Saegusa, Macromolecules, 8, 942 (1975).

4. (a) S. Kobayashi, K. Morikawa, and T. Saegusa, Polym. J., 11, 405 (1979); (b) S. Kobayashi, K. Morikawa, and T. Saegusa, Macromolecules, 8, 952 (1975).

5. (a) G. A. Olah, R. Molhotra, and S. C. Narang, $J$. Org. Chem., 43, 4628 (1978); (b) J. Kapsi, D. D. Montgomery, and G. A. Olah, J. Org. Chem., 43, 3147 (1978) and references cited therein. (c) M. Delmas, A. Denis, J. P. Gorrichon, and A. Gaset, Synth. Commun., 10, 517 (1980).

6. H. Hasegawa and T. Higashimura, Polym. J., 11, 737 (1979). 